\title{
Hipótesis sobre las funciones y la indumentaria de los po-re-na micénicos ${ }^{1}$
}

\author{
Juan PIQUERO RoDRÍGUEZ \\ Universidad de Alicante \\ jpiquero15@gmail.com
}

\section{RESUMEN}

Una vez rechazada la hipótesis, enunciada por Chadwick, de que los po-re-na eran individuos destinados a ser víctimas de un sacrificio humano, en el presente estudio se analizan cuáles podrían ser, verosímilmente, sus funciones. Se propone que serían personas que portaban ofrendas y asistían al sacerdote en los sacrificios. Posiblemente iban vestidos con una túnica de lino tal vez representada por el ideograma *146 o bien con un faldellín de lino, quizá representado por el ideograma *166+WE. Algunos llevaban sus vestidos sujetos con un ceñidor de lana.

Palabras clave: Religión micénica, po-re-na, sacrificios humanos.

\author{
Hypothesis about the functions \\ and clothes of mycenaeans po-re-na
}

\begin{abstract}
Chadwick formulated the hypothesis that the po-re-na were victims of human sacrifices, but this conjecture was rejected for some scholars. In this paper their possible functions are examined. It is proposed that the po-re-na were persons who carried gifts and assisted the priest at sacrifices. Possibly they wore a linen robe, maybe depicted by the ideogram *146, or a linen kilt, perhaps depicted by the ideogram *166+WE. Some po-re-na fastened their garments with a wool belt.
\end{abstract}

Keywords: Mycenaean religion, po-re-na, human sacrifice.

SUMARIO: 1. Introducción. 2. Estado de la cuestión. 3. Análisis lingüístico de los términos implicados. 3.1. po-re-na. 3.2. po-re-no-tu-te[. 3.3. po-re-no-zo-te-ri-ja. 3.4. po-re-si. 4. Contexto arqueológico. 5. Conclusión. 6. Imágenes. 7. Apéndice. 8. Bibliografía.

FECHA DE RECEPCIÓN: 17 DE 09 DE 2013 FECHA DE ACEPTACIÓN: 20 DE 11 DE 2013

\footnotetext{
${ }^{1}$ Este trabajo se enmarca en el proyecto «Estudio diacrónico de las instituciones religiosas de la Grecia Antigua y de sus manifestaciones míticas» (FFI 2013-41251-P). Quiero expresar mi más sincero agradecimiento a Alberto Bernabé, Eugenio R. Luján y Rachele Pierini por sus valiosas aportaciones en el desarrollo de este trabajo, de cuyos eventuales errores soy el único responsable.
} 


\section{INTRODUCCIÓN}

No es fácil aportar algún dato novedoso en relación con un tema tan manido en el ámbito de la micenología como lo son los po-re-na, unos individuos (hombres y mujeres) que, acompañados de distintos vasos de oro y de otro metal precioso, posiblemente plata ${ }^{2}$, aparecen en la tablilla de Pilo Tn 316 como ofrendas destinadas a varias divinidades ${ }^{3}$.

Con todo, en este trabajo vamos a intentar aportar una visión del término a partir del análisis lexicográfico de po-re-na (PY Tn 316), po-re-no-zo-te-ri-ja (PY Un 443.2), po-re-no-tu-te [ (PY Ua 1413), y la única atestiguación fuera de Pilo, po-re-si, en una tabilla de Tebas (Of 26).

Nuestro fin es intentar, en la medida de lo posible, desenmarañar la difícil cuestión de la dedicación de estos hombres y mujeres, sin duda de índole religiosa ${ }^{4}$, y contribuir a la corriente de opinión que enmarca las ceremonias relacionadas con los po-re-na en un ámbito cotidiano, y en absoluto excepcional ${ }^{5}$.

\section{ESTADO DE LA CUESTIÓN}

Desde que Chadwick enunciara su conocida teoría de que, con toda probabilidad, $\mathrm{y}$ «despite initial reluctance to accept the unpalatable fact ${ }^{6}$, estos individuos, los po$r e-n a$, estaban destinados a ser sacrificados, se han escrito inmensidad de trabajos a favor o en contra de tan arriesgada hipótesis, como veremos en el desarrollo de este mismo análisis.

Es bien sabido que Chadwick se basa en dos puntos fundamentales para sustentar esta teoría. Por un lado, el estado en que nos ha llegado el documento: escrito por las dos caras, con espacios en blanco y con varias faltas ortográficas cometidas por el escriba $^{7}$, entre otras $\operatorname{cosas}^{8}$. Por otro, el convencimiento al que el autor llega a partir del

\footnotetext{
2 Godart (2009), p. 112 y ss., Franceschetti (2012), pp. 243 y ss.

${ }^{3}$ Para un análisis breve y completo, de esta tablilla, que nos llevaría muy lejos de nuestro tema para este trabajo, cf. Weilhartner (2005) pp. 140 y ss

${ }^{4}$ Chadwick-Ventris (1956), pp. 284 y ss., (1973²), pp. 458 y ss., Chadwick (1976), pp. 89 y ss., Palmer (1963), pp. 265 y ss., especialmente Palaima (1999) con un repaso de la historia de la interpretación del documento en cuestión y donde se pone de manifiesto que hay acuerdo en pensar en un sentido religioso de la tablilla desde las primeras interpretaciones.

${ }^{5}$ Cf. especialmente Sacconi (1987) y Palaima (1995) y (1999).

${ }^{6}$ Chadwick (1976), p. 92.

${ }^{7}$ Por ejemplo en V.5, a por a-ke o pe-re-po-re-na-qe sin separador, en la misma línea.

${ }^{8}$ Chadwick (1976), p. 90. No es el objetivo de este trabajo hacer un análisis minucioso de la paleografía de PY Tn 316, que puede ser consultada en los trabajos de Chadwick-Ventris (1956), pp. 284 y ss., (1973²), pp. 458 y ss., Palmer (1963), pp. 261 y ss., Bennet (1979), Hiller (1991), Palaima (1995) y (1999), Gulizio (2000), Melena (2001), pp. 68 y ss., especialmente Duhoux (2008), p. 321 y ss. Cf. Godart (2009), con una nueva propuesta de lectura en $v .3$ na-ti-qe, Godart (2012), Olivier (2012) y Franceschetti (2012). Pero cf. PofN $I V$ donde no se acepta la lectura.
} 
análisis de distintos testimonios ${ }^{9}$ que, a su parecer, indican el «estado de emergencia» del reino pilio poco antes de la caída del palacio ${ }^{10}$.

Según esta teoría, PY Tn 316 sería uno de los últimos documentos escritos en Pilo $^{11}$, y está escrito de una manera tan desordenada porque el escriba «was trying to record the decisions of an unusually stormy meeting $\rangle^{12}$. Si nos preguntamos por qué no hizo una copia en limpio de este «borrador», «the most likely answer is that he had no time» ${ }^{13}$.

Pues bien, muchos estudios posteriores han dudado de la verosimilitud de tal hipótesis, como vamos a ver inmediatamente.

En cuanto a la forma del documento, ciertamente un tanto descabalada, Bennett $^{14}$ opina que el escriba, la mano 44, recoge el texto de otras tablillas y lo reúne en ésta de un modo más sucinto. Hemos de admitir, que aunque el texto, como veremos, no parece estar escrito en una «situación de emergencia», realmente es difícil discernir por qué el escriba eligió darle esa forma que le da la apariencia de incompleto ${ }^{15}$.

Godart $^{16}$, después de un minucioso análisis del texto, concluye que en realidad hay dos escribas, y tal vez es esa la explicación para entender que, mientras el recto de la tabilla parece redactado bastante cuidadosamente (el escriba no se «tuerce» en las líneas marcadas como guía), el verso, que contiene mayor información, sea el que está, con diferencia, peor redactado, incluso con faltas de ortografía, como decíamos ${ }^{17}$.

Hay dos estudios fundamentales, a nuestro juicio, que desde un punto de vista epigráfico han determinado que la hipótesis de Chadwick es poco probable, ambos a cargo de Palaima y con un profundo estudio del archivo. En el primero ${ }^{18}$ niega la situación de excepcionalidad de los documentos en los que Chadwick se basaba ${ }^{19}$ a partir del análisis de los registros, de donde deduce que hay documentos que entraron en éste con posterioridad, como la serie Sh, sobre reparación de armaduras, la Ta, un inventario de muebles y enseres destinados a un banquete festivo, Es, con ofrendas a

\footnotetext{
${ }^{9}$ PY Tn 316, Jn 829, en relación con el posible uso del «bronce del templo» para hacer armas, y la serie conocida como $o$ - $k a$ (An 657, 654, 519, 656 y 661, según la reconstrucción de Chadwick [1976:175]), que verosímilmente indicaría una situación especial, en la idea de que la costa se vigila por temor a un ataque inminente. Sobre el citado «bronce del templo», cf. el interesante trabajo de Del Freo (2005), con un repaso a las hipótesis propuestas y una nueva interpretación: el bronce sería para las armas de la flota de Pilo.

${ }^{10}$ Cf. Chadwick (1976), pp. 191-192 para un resumen somero de la situación.

${ }^{11}$ Dice literalmente Chadwick «the tablets were written within the last few days, perhaps the last few hours» [1976:90].

12 Chadwick (1976), p. 90.

13 Chadwick (1976), p. 90.

14 Bennett (1979).

15 Palaima (1999) pp. 444 y ss. ofrece una explicación convincente al hablar del escriba 44, pero como mucho podríamos admitir una peculiaridad excepcional de esta «mano» ante el corpus micénico.

16 Godart (2009).

17 Cf. n. 7.

18 Palaima (1995).

19 Cf. n. 9.
} 
Posidón y Un 718, con más ofrendas a Posidón, realizadas en este caso por e-ke-ra $a_{2}$ wo, tal vez el rey de Pilo. Propone también Palaima que los po-re-na son «sacristanes», portadores que llevan los vasos ofrendados y que estarían dedicados al culto de la divinidad ${ }^{20}$.

En su otro trabajo sobre este documento ${ }^{21}$, además de hacer un detenido análisis de los hechos que singularizan esta tablilla y que hacen que su interpretación sea compleja, se centra en el valor religioso de ésta, fundamentado especialmente en la cantidad y calidad de ofrendas que registra así como en el número de divinidades que aparecen como receptoras, proponiendo establecer una jerarquía de éstas a partir de los parágrafos de la tablilla y la tipología de las copas ofrendadas.

Sacconi ${ }^{22}$ había advertido la posibilidad de que estos individuos tuvieran la doble función de ser dedicados como ofrendas a una divinidad, como «sacerdoti e sacerdotesse», y además portaran los vasos con ellos, aunque da cuenta con razón de que hay tres divinidades (ti-ri-se-ro-e, do-po-ta e i-pe-me-de-ja $)^{23}$ que sí tienen una asignación de vasos pero no de personas. Sugiere que serían divinidades menores que no tendrían asignadas «sacerdoti e sacerdotesse» en la fiesta, y a falta de una mejor explicación, creemos que es la más convincente, aunque con algunas puntualizaciones más sobre su función que haremos más adelante ${ }^{24}$.

\section{ANÁLISIS LINGÜÍSTICO DE LOS TÉRMINOS IMPLICADOS}

\section{1. po-re-na (cf. Apéndice)}

El término se atestigua en PY Tn 316 (r. 2, v. 2. 5. 8):

recto

02. i-je-to-qe, pa-ki-ja-si, do-ra-qe, pe-re, po-re-na-qe pu-ro

verso

02. do-ra-qe, pe-re, po-re-na-qe, a-ke

a. -qe

05. do-ra-qe , pe-re-po-re-na-qe,a,pe-re-*82 AUR *213 VAS 1 MUL 1

08. i-je-to-qe, di-u-jo, do-ra-qe, pe-re, po-re-na-qe a-ke

\footnotetext{
20 Palaima (1995), p. 628.

21 Palaima (1999).

22 Sacconi (1987), p. 554.

23 Aunque Sacconi no lo incluye, tampoco di-ri-mi-jo en $v .10$ recibe una persona entre las ofrendas, sino sólo un vaso de ¿plata? del tipo *213 ${ }^{\text {VAS }}$. Cf. Godart (2009), p. 103.

${ }^{24}$ Dejamos fuera del este breve repaso, porque la consideramos poco probable, la hipótesis de Nagy (199495) y Willi (1994-95) sobre que hemos de entender po-re-na como un infinitivo. Cf. también la crítica de Palaima (1995-96).
} 
Pensamos, como la mayoría de los autores, que hemos de reconstruir un sustantivo * $\varphi$ en griego ${ }^{25}$. Entre los significados que puede aportar este sufijo, Balles en su estudio sobre formación de palabras, plantea las siguientes posibilidades para los términos en - $\eta v$ : Personenbezeichnungen, Tiere, Körperteile und Sachen, o Personennamen ${ }^{26}$. Creemos que el de Personenbezeichnungen, y en concreto el tipo nomen agentis (tipo

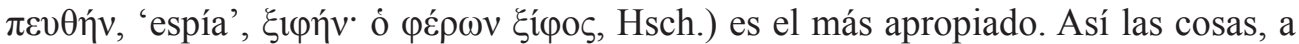
partir de un significado 'ofrecer' o 'conceder un favor', que está atestiguado para

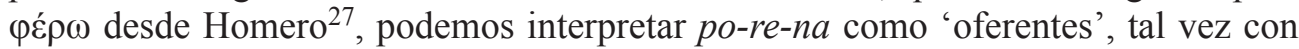
un doble sentido, esto es, seguramente estos individuos son los que llevan los vasos de oro y el otro metal precioso (¿plata?) ${ }^{28}$, como sugieren Sacconi y Palaima ${ }^{29}$, pero pensamos que también son ofrecidos al templo para llevar a cabo algún trabajo en relación con el culto. Tales funciones serían las de prestar algún tipo de servicio al templo, posiblemente de tipo secundario, es decir, no son sacerdotes, sino más bien «asistentes» o «sacristanes», como propone Palaima ${ }^{30}$, tal vez, como veremos, con la función de ofrecer sacrificios, aunque podrían también desempeñar otras semejantes. Si la función principal de los po-re-na fuera simplemente llevar los vasos que aparecen en el documento, no tendría sentido la especificación de estos individuos en la tablilla por medio de los ideogramas VIR y MUL, como bien apunta Sacconi ${ }^{31}$, pues es obvio que los vasos tendrían que ser llevados por alguien que no sería especificado por escrito a menos que el propio individuo fuera también algún tipo de «ofrenda», como parece sugerir el texto ${ }^{32}$.

Se ha puesto de manifiesto también el hecho de que a las divinidades masculinas les son ofrecidos hombres, mientras que a las femeninas, mujeres ${ }^{33}$.

Chadwick ampara su hipótesis de «víctimas humanas» sobre la base de un sustantivo dor. $\varphi \varepsilon \rho v \overline{\bar{\alpha}}$, 'porción de víctima reservada a la divinidad' ${ }^{34}$, atestiguado en dos inscripciones de Epidauro de finales del s. V a.C., donde se habla de unas ofrendas de cebada que han de hacerse a Apolo y a Asclepio ${ }^{35}$. Asociar este sentido, el de una

\footnotetext{
25 Chantraine (1933), p 166 y ss.

26 Balles (2008), p. 208.

${ }^{27}$ Od. 8. 428 para 'ofrecer' e Il. 5.211; Od. 5.307. Cf. además Chantraine Dict. Etým. s.v. «“apporter”, d'où "offrir" un cadeau (sens attesté en myc.)»).

28 Cf. n. 2.

29 Sacconi (1987) y Palaima (1995) y (1999).

${ }^{30}$ Palaima (1995), p. 628.

31 Sacconi (1987), pp. 553-4.

32 Los escribas, como parece lógico, no anotan en la tablilla a los individuos que llevan los vasos como ofrenda. Así en la misma tablilla PY Tn 316 aparecen cuatro divinidades (tal vez de menor importancia, como decíamos) que sí tienen asignación de vasos pero no de personas: $r .5$ ti-ri-se-ro-e y do-po-ta; v. 6 i-pe-me-deja, v. 10 di-ri-mi-jo. También en KN Gg (1) 702, donde aparecen sendas ofrendas de vasos del tipo *209VAS a pa-si-te-o-i y a da-pu,-ri-to-jo po-ti-ni-ja no aparece anotado el «portador» del vaso, pues parece que en este caso la ofrenda es sólo de los vasos y no de vasos e individuos.

33 Chadwick (1973), p. 460, (1976), p. 91-92.

${ }^{34}$ DMic. s.v.

${ }^{35} I G \mathrm{IV}^{2}$ 40.6; 41.7. cf. también Sokolowski (1969), pp. 113-114.
} 
ofrenda cotidiana de cebada, al de un sacrificio humano nos resulta un poco forzado y ofrecido ad hoc ${ }^{36}$.

Una pista en relación con las tareas que llevaría a cabo los po-re-na nos la da el término po-re-no-tu-te [, que pasamos a analizar.

\section{2. po-re-no-tu-te [}

Desgraciadamente la tabilla está rota y la palabra incompleta, lo que ha dado lugar a distintas propuestas, entre las que se admite de forma general una reconstrucción po-re-no-tu-te[-ri-ja, que se interpreta generalmente como el nombre de una fiesta ${ }^{37}$.

La tablilla nos informa de lo siguiente:

$$
\text { PY Ua } 1413
$$

.a

$$
\begin{aligned}
& * 1467 * 166+\mathrm{WE} 1[ \\
& \text { ro-u-si-jo a-ko-ro, po-re-no-tu-țẹ[ }
\end{aligned}
$$

Así pues, a pesar de lo fragmentario de la información, tenemos siete telas del tipo *146 (fig. 3) y una 166+WE (fig. 4), que suelen aparecer juntas en contextos religiosos ${ }^{38}$ y que han sido interpretadas generalmente como «telas de lino» ${ }^{39}$.

El hecho de que $W E$, que posiblemente hace referencia al sustantivo we- $a_{2}-n o^{40}$, aparezca en relación con los ideogramas *146 y *166 lleva a Melena, en la misma línea que ya se explicara Chadwick ${ }^{41}$, a concluir que «the name $w e-a_{2}$-no indicates an indeterminate type of linen fabric capable of assuming the forms $* 146$ and $* 166 »{ }^{42}$,

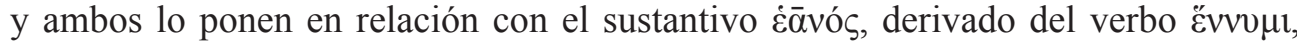
'vestirse' (IE *wes- : lat. vestis, ai. váste).

${ }^{36}$ Para otras interpretaciones, cf. DMic. s.v. po-re-na-qe, n. 4.

${ }^{37}$ Cf. DMic. s.v. Cf. también Palaima (1999), p. 455, que propone una restitución po-re-no-tu-te [-ri-jo-i y Nosch-Perna (2001) p. 473, donde Perna propone un dat. sing. po-re-no-tu-te [-ri, * sacrificer'.

${ }^{38}$ Nosch (2012), p. 341-2 y Nosch-Perna (2001). También Duhoux (1976), p. 122, así como Killen (2008), p. 442, que trata sobre la presencia del ideograma *146 en un contexto de «military equipment». En su argumentación plantea que el hecho de que $* 146$ aparezca también en este contexto, y no sólo en el religioso (donde está atestiguado, sin embargo, de forma mayoritaria), parece indicar que el estado provee de ropa a los trabajadores dependientes o semi-dependientes, ya sean sus funciones religiosas o militares.

${ }^{39}$ Cf. Nosch (2012) donde se recogen las interpretaciones dadas a los ideogramas textiles desde el desciframiento y se hace una puesta al día. Para una interpretación de estos ideogramas como referidos a pieles en lugar de a tejidos cf. Sacconi (1967), especialmente pp. 115 y ss. y Bernabé-Luján, en prensa. Cf. críticas a la interpretación de Sacconi en Duhoux (1976), pp. 118 y ss.

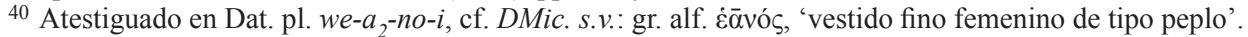

${ }^{41}$ Chadwick (1964), p.25, «Possibly [...]*146 is normally of linen but is a woven (and possibly stitched) piece of linen of a particular shape».

42 Melena (1975), p. 62. 
Duhoux, sin embargo, concluye que el ideograma *146 hace referencia a un «vêtement» ${ }^{43}$ y no a un simple tejido de lino sin elaborar, entendiendo igualmente que we- $a_{2}$-no tiene relación con el gr. alf. $\dot{\varepsilon} \bar{\alpha} v o ́ s$. En cuanto a *165-*166, que él agrupa, pues por su forma «il parait difficile de considérer *165 y*166 comme deux idéogrammes distincts» ${ }^{44}$, piensa que hacen referencia a los faldellines que visten algunos individuos que aparecen en el «Fresco de la Procesión» de Cnoso ${ }^{45}$.

En vista de la dificultad que supone a los estudiosos definir el material del que está fabricado dicho atuendo, y si éste es una suerte de «tela sin confeccionar»o de vestido ya elaborado, Nosch y Perna deducen a partir de los datos de los textos ${ }^{46}$ que existen varios tipos de $w e-a_{2}$-no en cuanto al material (lino o lana), calidad, y modelo, esto es, largo, medio y corto ${ }^{47}$.

Más adelante intentaremos poner en relación este tipo de atuendo con las ceremonias de los po-re-na a partir de los testimonios arqueológicos (§4).

En cuanto a ro-u-si-jo a-ko-ro, es uno de los distritos de Pilo que está vinculado de alguna manera con ritos religiosos ${ }^{48}$.

Creemos que el análisis del término po-re-no-tu-tẹ[-ri-ja, dativo singular o nominativo de rúbrica, puede aportarnos algún dato más en relación con la función de los po-re-na. Si entendemos, como es común ${ }^{49}$, que el segundo término del compuesto tiene que ver con $\theta v ́ \omega$, 'sacrificar', tal vez podamos hacernos una idea más aproximada de las funciones que estos individuos desempeñaban en el templo.

Este tipo de compuestos en - $\tau$ ńpıov, que pueden aparecer sustantivados también

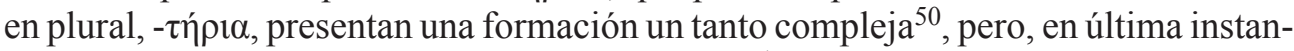
cia, la mayoría son derivados de una base verbal ${ }^{51}$. Es relativamente común que con

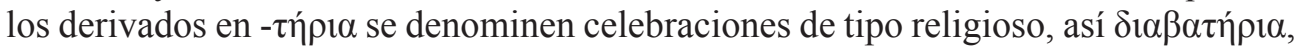

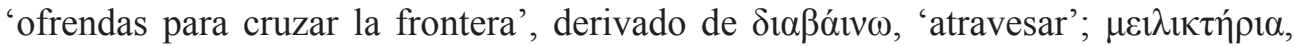

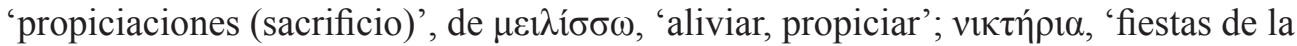

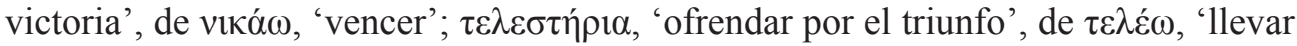

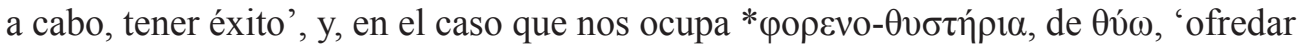
mediante combustión'.

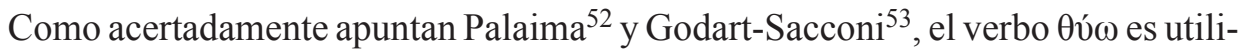
zado en Homero para referirse a ofrendas hechas mediante combustión en la creencia

\footnotetext{
43 Duhoux (1976), p.122.

44 Duhoux (1976), p. 123.

45 Duhoux (1976), pp. 130 y ss.

${ }^{46}$ Cf. Nosch (2012) s.v. *146 y *166 para una lista de los textos donde aparecen los ideogramas.

47 Nosch-Perna (2001), p.477. Sin embargo, Nosch (2012), p.340 «this, however, does not give any conclusive evidence of the fibre of $* 146 »$.

${ }^{48}$ PY Un 47 con provisiones para un banquete y PY Fr 1220 y 1226 con envíos de aceite perfumado relacionados con di-pi-si-jo-i wa-na-ka-te y te-o-i.

49 DMic. s.v.

${ }^{50}$ Cf. Ruiz Abad (2013), p. 136 y ss. para una catalogación de la formación de este tipo de términos.

51 Ruiz Abad (2013), p. 174.

52 Palaima (1999), p. 455, n. 62.

53 Godart-Sacconi (1998).
} 
de se quema algo para que el humo suba al cielo y sirva como alimento a los dioses ${ }^{54}$, aunque más tarde es usado simplemente con el significado de 'sacrificar' 55 . De he-

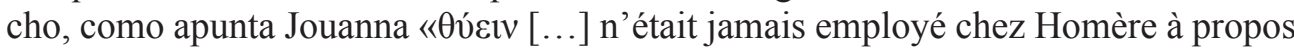
des sacrifices sanglants, mais s'appliquait, conformément à son sens étymologique (racine *dhu- que l'on trouve aussi dans le latin fumus), aux offrandes non sanglantes que l'on fait fumer» ${ }^{56}$. Chantraine precisa que «le verbe est rare chez Homère [...] où il désigne toujours l'offrande aux dieux par combustion, notamment de nourriture ou de prémices $\rangle^{57}$, pues el verbo técnico usado para referirse al sacrificio, más concretamente al acto de 'degollar' a la víctima, es $\sigma \varphi \alpha ́ \zeta \omega^{58}$.

Así las cosas, creemos que, efectivamente, la función principal de estos individuos en los distintos santuarios que aparecen en la tablilla, concretamente seis ( $p a-$ ki-ja-ne, po-si-da-i-jo, pe-re-*82-jo, i-pe-me-de-ja-qe, di-u-ja-jo-qe, di-u-jo), es la de llevar a cabo sacrificios posiblemente no sangrientos, sino que tal vez, a partir de lo visto sobre el significado de $\theta$ v́ $\omega$ en Homero, quemaran ofrendas para la divinidad ${ }^{59}$.

Pensamos que podemos interpretar po-re-no-tu-te [-ri-ja como 'las fiestas de los sacrificios de los oferentes', sin necesidad de creer por ello que lo que ocurre en éstas es que «sacrifican a los po-re-na», esto es, un sacrificio humano ${ }^{60}$, sino que en estas fiestas unos cuantos individuos se ponen al servicio de la divinidad, no sabemos por cuánto tiempo ni en qué condiciones, para asistir a los sacerdotes del templo como «sacristanes», o algo similar ${ }^{61}$, dedicados a ofrendar mediante sacrificios por combustión.

Pasemos a ver ahora otra información que nos brindan las tablillas: cómo, verosímilmente, iban vestidos los po-re-na.

\section{3. po-re-no-zo-te-ri-ja}

El término se atestigua en PY Un 443:

$$
\begin{aligned}
& .1 \text { ku-pi-ri-jo, tu-ru-pte-ri-ja, o-no LANA } 10 * 14610 \\
& .2 \text { po-re-no-zo-te-ri-ja LANA } 3 \\
& .3 \text { ]ḍo-ke, ka-pa-ti-ja , HORD } 2 \text { te-ri-ja GRA } 1 \text { LANA } 5
\end{aligned}
$$

\footnotetext{
${ }^{54}$ De hecho, en el pensamiento mitológico, cuando hay algún problema en la tierra y los hombres no hacen ofrendas, los dioses, antes de empezar a «pasar hambre», intentan poner alguna solución. Cf. así por ejemplo en Himno homérico a Deméter, vv. 310 y ss. o el mito de Hedammu que conservamos en los textos hititas. Para este último, cf. Bernabé (1987), pp. 157 y ss. y (2008), pp. 310 y ss.

${ }^{55}$ Chantraine, Dict. Étym. s.v.

${ }^{56}$ Jouanna (1992), p. 414

${ }^{57}$ Dict. Étym. s.v.

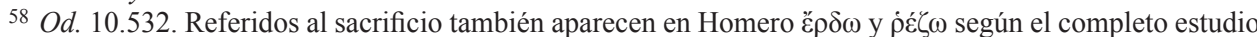
de Jouanna (1992), pp. 412 y ss.

${ }^{59}$ Godart-Sacconi (1998), p. 604: «Il verbo $\theta 0 ́ \omega$ in Omero si riferisce sempre a cibi solidi di diversa natura adatti alla combustione: carne, formaggio, farina, ecc».

${ }^{60}$ Duhoux (1976), p. 128.

${ }^{61}$ Sacconi (1987), p. 554.
} 
Tanto en PY Un 443.2 como en TH Of 26, como veremos después (§3.4), los pore-na aparecen como destinatarios de medidas de lana.

En la tablilla de Pilo nos encontramos con un antropónimo ku-pi-ri-jo, probablemente un «collector», a quien, según propone Killen ${ }^{62}$, el palacio da un pago en diez unidades de lana y diez telas o vestidos $* 146$ a cambio de un o-no ${ }^{63}$ de tu-ru-pte-ri-ja, interpretado generalmente como 'alumbre' ${ }^{64}$.

En la línea 2 de la tabilla tenemos el término po-re-no-zo-te-ri-ja, acompañado del ideograma de la lana y el numeral 3.

No está claro que la tablilla haga referencia a una sola entrega, esto es, a la de $k u$-pi-ri-jo, fundamentalmente porque en la línea 3 de esta misma tablilla aparecen otros dos antropónimos, ka-pa-ti-ja y te-ri-ja, que reciben, o bien entregan al palacio dos unidades de cebada, y una de trigo y cinco de lana respectivamente.

La cuestión es, entonces, si po-re-no-zo-te-ri-ja tiene que ver también con la entrega que se hace a ku-pi-ri-jo, o si, simplemente, hay una lista de envíos o entregas al palacio que se han dado en el mismo día y que el escriba anota juntos sin que tengan que tener necesariamente otra relación que la meramente temporal. Si pensamos que sí tienen relación, vemos que una vez más el ideograma *146 aparece vinculado de alguna forma a los po-re-na y al ámbito de lo religioso.

En cualquier caso, creemos que hay que interpretar po-re-no-zo-te-ri-ja como

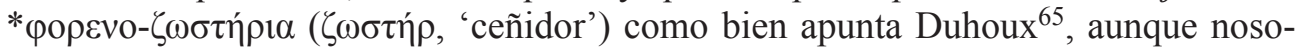
tros disentimos de éste en su traducción. Mientras él, siguiendo la teoría de Chadwick, interpreta que po-re-na significa 'víctima', de lo que traduce 'bandelettes pour victimes', nosotros, como ya hemos dicho, interpretamos que significa 'oferentes', de modo que entendemos el texto como 'tres piezas de lana para los ceñidores de los oferentes'.

Este tipo de formación con el sufijo - $\tau$ ńpıov para la formación de nombres de instrumento está ampliamente documentado en griego del primer milenio ${ }^{66}$, así

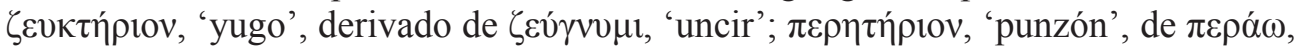
'perforar'; $\chi \varepsilon \dot{\varepsilon} \mu \alpha \sigma \tau \rho o v$, 'prenda de invierno', de $\chi \varepsilon \mu \alpha \alpha ́ \zeta \omega$, 'invernar'; y en el caso que

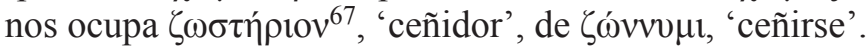

A partir de lo visto sobre la interpretación del documento, parece razonable que el palacio diera (o recibiera en calidad de pago destinado concretamente a esa actividad religiosa) lana para la fabricación de los cinturones con los que habrían de ceñirse los «oferentes», o al menos algunos de ellos ( $\$ 4)$, habida cuenta de la importancia que parecen tener las procesiones descritas en PY Tn 316, por su elevado número, por la cantidad de dioses a los que se atiende, por la calidad de los regalos-reliquia que se

\footnotetext{
62 Killen (1995),

${ }^{63}$ Cf. DMic. s.v. para un catálogo de interpretaciones de este intrincado término. Tal vez 'pago, retribución'.

64 Cf. DMic. s.v. para otras interpretaciones menos plausibles.

65 Duhoux (1976), pp. 127-8.

${ }^{66} \mathrm{Cf}$. también lo dicho en $\S 3.2$ sobre la formación de nombres de ceremonias sobre este sufijo.

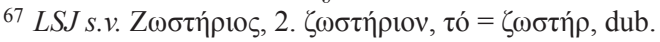


ofrendan ${ }^{68}, y$, finalmente, por el hecho de que se ofrezcan también personas destinadas al culto y ritual del dios al que se ofrecen.

\section{4. po-re-si}

También en Tebas (Of 26), tenemos atestiguados a estos po-re-na, en la forma del dativo plural po-re-si:

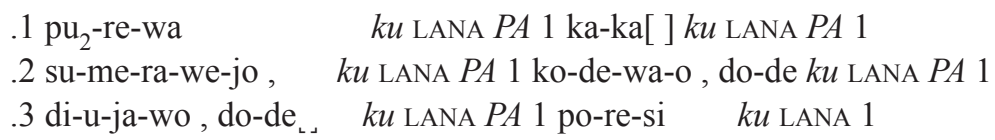

Los po-re-na reciben en este caso una unidad de lana $k u$, es decir, de ambos testimonios, el pilio y el tebano, se desprende algún tipo de relación de estos individuos con la lana.

Esta atestiguación del dativo plural po-re-si en Tebas como destinatarios de lana, lleva a Chadwick a admitir que también hay sacrificios humanos en Tebas: «since sacrificial victims in Greek ritual were frequently decked out with wool, this is some slight confirmation of the meaning of the word», dice ${ }^{69}$. El hecho de que tuviéramos testimonio escrito de sacrificios humanos en Pilo y Tebas, donde no se dan los condicionantes de una «situación de emergencia» como la descrita para $\mathrm{Pilo}^{70}$, nos conduciría a pensar que éstos debían de ser cotidianos en la Grecia del segundo milenio a.C., lo que pensamos que es suponer demasiado ${ }^{71}$.

No es que con esto queramos decir que no existen sacrificios humanos en el mundo religioso griego, cosa bien atestiguada tanto por los mitos como por los restos arqueológicos ${ }^{72}$, incluso hasta bien entrada la época clásica ${ }^{73}$, sino que creemos que no eran habituales, cotidianos, que, efectivamente, responderían más bien a una situación excepcional o de emergencia que no aparece reflejada en los textos micénicos.

Pensamos, por el contrario, que la lana que se da a los po-re-na en ambas atestiguaciones es para fabricar ceñidores, cinturones, de ahí el compuesto po-re-no-zote-ri-ja. Sabemos que el acto de ceñirse con un cinturón tiene en la Grecia antigua un carácter apotropaico o mágico, y por esto forma parte del ritual religioso y de los guerreros ${ }^{74}$. Es, de algún modo, un símbolo que hace que quien lo porte esté más

\footnotetext{
68 Coincidimos con Sacconi (1987), p. 553 en que, probablemente, los vasos que se llevaban en la procesión pertenecían «al tesoro sacro del Palazzo e sono definiti do-ra, cioè 'doni', nel senso di offerte votive fatte in precedenti occasioni alle divinità e come tali acquisite al tesoro sacro».

${ }^{69}$ Chadwick (1976), p. 92.

70 Chadwick (1976), pp. 89 y ss.

${ }^{71}$ En esta misma línea de pensamiento sobre sacrificios humanos cotidianos, cf. Buck (1989).

72 Hughes (1991), Bonnechere (1994), Sakellarakis- Sapouna Sakellaraki (1981).

73 Cf. Plutarco Temístocles 13, para un sacrificio de tres jóvenes antes de la batalla de Salamina.

${ }^{74}$ Burkert (2011), p. 154: el sacerdote suele llevar «un cinturón especial».
} 
unido a la divinidad, ceñirse un cinturón hace que el individuo se sitúe por encima del plano de los mortales y pueda acercarse más a la divinidad, que lo protege. Tenemos también testimonios, aunque tardíos para el ámbito en el que nos movemos aquí, de su uso entre los seguidores de Dioniso y los órficos, incluso conservamos un poema titulado Sobre el cinturón atribuido a $\mathrm{Orfeo}^{75}$ donde, posiblemente, se

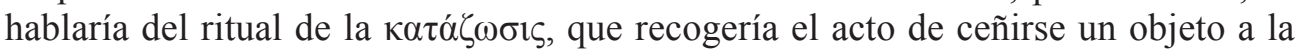
cintura $^{76}$.

No es raro, pues, que algunos de los denominados po-re-na se ciñeran con un cinturón unos «hábitos» que, posiblemente, son los que aparecen atestiguados en la ya examinada tablilla PY Ua 1413, esto es, las telas que representan los ideogramas *146 y *166+WE que han sido interpretados generalmente, como decíamos (§3.2), como «telas o vestidos de lino», aunque a continuación vamos a perfilar un poco más cómo creemos que estas telas se distribuyen entre los po-re-na.

\section{CONTEXTO ARQUEOLÓGICO}

Pensamos que para hacernos una idea más certera sobre los «hábitos» que presumiblemente llevaban los po-re-na, tenemos que dedicar un espacio a las atestiguaciones arqueológicas. Existen restos de frescos ${ }^{77}$ e imágenes de individuos celebrando procesiones, o bien desempañando labores de tipo cultual.

Si entendemos, con Chadwick y Melena ${ }^{78}$ (\$3.2) que los ideogramas *146 (fig. 3) y *166 (fig. 4) hacen referencia a una «tela de lino» aún sin elaborar, podemos deducir que tal vez con ellas pudieran fabricarse faldellines semejantes a los que aparecen habitualmente en relieves y frescos micénicos ${ }^{79}$, que suelen ir ceñidos, además, con un cinturón ${ }^{80}$, como los que tenemos representados en una pintura de un rhyton de Cnoso (fig. 1) de la que hablaremos inmediatamente.

Otra opción que creemos mejor es pensar con Duhoux ${ }^{81}$, que estos faldellines estarían representados con el ideograma $* 166+W E$, que también tenemos atestiguado en relación con los actos de los po-re-na (\$3.2).

Por otra parte, si pensamos con Nosch-Perna ${ }^{82}$ que «the ideogram $* 146$ with its upper triangle reminds mostly of the Mycenaean tunic with a hole cut out for the head» ${ }^{83}$, podríamos pensar en una especie de túnica parecida a la que visten los indi-

\footnotetext{
75 Jiménez San Cristóbal (2008), pp. 766-7.

76 Boyancé (1966), pp. 45 y ss.

${ }^{77}$ Lang (1969), pp. 51 y ss.

78 Cf. notas 41-42.

${ }^{79}$ Parece que este tipo de prenda tendría un origen minoico. Cf. Marinatos (1967) A 22 y ss. y, más recientemente Rehak (1996), p. 42 y ss.

${ }^{80}$ Cf. Marinatos (1967), A 22 y ss.

81 Duhoux (1976), pp. 130 y ss.

82 Nosch-Perna (2001), p.476.

${ }^{83}$ Cf. Nosch (2012) p. 338 para los distintos modelos de ideogramas del tipo *146 en función de los escribas.
} 
viduos que aparecen representados portando también objetos en una procesión en el fresco del vestíbulo noreste del palacio de Pilo ${ }^{84}$ (fig. 2), aunque estos no llevan un cinturón ciñéndoles la ropa.

De aquí deducimos que verosímilmente sólo algunos de los po-re-na irían ceñidos con un cinturón, en concreto los que llevan el faldellín que parece representar el ideograma $* 166+W E$, mientras que el resto vestiría una túnica de lino del tipo que representa el signo $* 146$, sin ceñir.

Como ejemplo de lo que parecen unos po-re-na con un faldellín, destaca un testimonio $^{85}$ (fig. 1). En las excavaciones efectuadas por Evans en Cnoso ${ }^{86}$, salió a la luz un rhyton con un relieve donde aparecen unos individuos que avanzan en lo que podría ser una procesión. Portan en sus manos un vaso cada uno, más concretamente lo que podríamos llamar un «cuenco» ${ }^{87}$, y van vestidos con algo así como un faldellín, que podría ser precisamente de lino como el representado por $* 166+W E$, y ceñidos con un cinturón que lo sujeta, tal vez fabricado con lana.

Más datos nos aporta el citado fresco del Palacio de Pilo (fig. 2), pues en él tenemos representados una serie de individuos, hombres y mujeres, que participan en una procesión. Como se ve, aparecen hombres ataviados con túnicas y otros con faldellines ceñidos con un cinturón, tal vez de lana. También mujeres que llevan una túnica que parece semejante a la de los hombres, aunque ceñida con un cinturón.

A nuestro juicio, como ya hemos dicho, si entendemos que la dedicación de los po-re-na es cotidiana y en absoluto excepcional, y teniendo en cuenta el número de procesiones en que aparecen en PY Tn 316, podríamos pensar, que sin estar representada en este fresco ninguna de las procesiones que nos describe el documento (nada se nos dice del toro que aquí ocupa un primer plano), verosímilmente los individuos, mujeres y hombres, que aparecen representados portando objetos son precisamente po-re-na, o, al menos, algunos de ellos. Vemos, además, que sólo los que portan el faldellín que parece representar el ideograma $* 166+W E$ van ceñidos con los cinturones de lana que proponemos aquí. El resto de hombres llevaría una túnica del tipo *146 de lino y sin cinturón. Las mujeres parecen llevar una túnica semejante a la de los hombres, aunque ceñida con un cinturón que tal vez fuera de lana.

Esta representación de Pilo daría aún más fuerza a la opinión de que en los documentos los po-re-na estén asociados a las ropas que pueden notar los ideogramas $* 146$ y $* 166+W E^{88}$, pues también en ella vemos que este tipo de prendas están íntimamente asociadas al ámbito religioso.

\footnotetext{
${ }^{84}$ Lang (1969), pp. 64 y ss. y Pl. 119 con una reconstrucción.

85 También Weilhartner (2005), pp.140 y ss. pone en relación los po-re-na con la imagen que aparece en este vaso.

${ }^{86}$ Evans (1928), p. 752, fig. 486.

${ }^{87}$ Representado en micénico con el ideograma $* 213^{V A S}$, que aparece también como uno de los vasos de oro y otro metal precioso (¿plata?) ofrendados en la tabilla PY Tn 316. Cf. Vandenabeele-Olivier (1979), p. 183 para este tipo de «cuencos».

${ }^{88}$ Cf. n. 38 .
} 


\section{CONCLUSIÓN}

A partir de lo dicho, nos parece probable que el término po-re-na designe a personas que desempeñaban una función que no tiene un carácter excepcional dentro de la religión micénica. Más bien parecen individuos con una doble función: por un lado participar en las procesiones que nota PY Tn 316 como portadores de los vasos que allí se documentan; y en segundo lugar, a partir de la explicación de po-re-no-tu-tẹ[ri-ja como un compuesto con $\theta 0 ́ \omega$, servir como asistentes de los sacerdotes en rituales de sacrificio con fuego, no necesariamente sacrificios cruentos ${ }^{89}$.

En cuanto a su indumentaria, verosímilmente, unos irían vestidos con túnicas del lino del tipo que parece representar el ideograma $* 146$, mientras que otros llevarían un faldellín de lino que probablemente esté representado por el ideograma $* 166+W E$, ceñido con un cinturón de lana, y, en el caso de las mujeres, una túnica de lino ceñida con un cinturón de lana.

Tanto las telas o vestidos $* 146$ y $* 166+W E^{90}$ como el acto de ceñirse están íntimamente ligados al ámbito ritual. Como decíamos (\$3.3), los documentos parecen sugerir además que las ropas son entregadas a los po-re-na por la administración.

Posiblemente la función de estos 'oferentes' es principalmente la de asistir al sacerdote en algunas funciones, principalmente la de ofrecer sacrificios, de ahí que tengamos constancia de una fiesta que, si es que reconstruimos bien la tablilla PY Ua 1413, hemos de interpretar como la 'fiesta de los sacrificios de los oferentes', pues es esa, la de ser ofrecidos para hacer sacrificios, una de sus principales tareas, junto con la de portar los vasos durante las procesiones.

El hecho de que haya una fiesta 'de los po-re-na', esto es, po-re-no-tu-te [-ri-ja, y que sea la ciudad la que da los «hábitos» a los 'oferentes' (§3.3), puede indicar también que tal vez éstos se dedicaran a esta tarea de manera ocasional, es decir, tendrían otro trabajo. Tal vez, como nuestros «cofrades» en las fiestas de Semana Santa, ejercen como «asistentes», «sacristanes» o, en cualquier caso, «persone legate con l'attività cultuale»» ${ }^{91}$ durante sólo un periodo de tiempo, durante las fiestas que sean, cualquiera de las que aparece en PY Tn 316. Una vez acabada la fiesta, ellos vuelven a sus tareas y son los sacerdotes quienes ejercen el culto a la divinidad. Es bien sabido que, incluso hoy, en las celebraciones religiosas siempre son necesarios ayudantes que asistan las tareas que le sean encomendadas por el sacerdote, por ejemplo los «monaguillos». Como decimos, posiblemente esta tarea de 'oferente' se prolongara tal vez sólo el día (o días) de la fiesta.

\footnotetext{
${ }^{89}$ De este tipo de rituales de sacrificio con fuego tenemos posiblemente un paralelo en la discutida tablilla de Tebas TH Fq 126.1, o-te tu-wo-te-to, 'cuando celebraron el sacrificio (con fuego)', donde parece que se hace referencia a una ceremonia ritual semejante a la que creemos que podrían desempeñar los po-re-na. En esta línea de interpretación de la tablilla tebana, cf. M. Lejeune, Mém. IV, 274; TOP I 184; Ruijgh (2004), pp. 24-27 y Bernabé-Serrano (2011), pp. 22-23.

90 Cf. n. 38.

91 Sacconi (1987), p. 554.
} 
Como vemos, las procesiones y ofrendas de las que versa el documento no forman parte de ninguna «situación de emergencia», sino más bien del ámbito cotidiano de las fiestas que coincidieron en el mismo mes po-ro-wi-to-jo de Pilo, del que nos habla el encabezamiento de PY Tn 316. Tampoco esto ha de sonarnos raro, pues bien pueden coincidir en nuestro tiempo, en un mismo mes y ciudad, pongamos Abril y Sevilla, la Semana Santa y la fastuosa «Feria de Abril».

Finalmente, el hecho de los po-re-na no aparezcan sólo en los documentos de Pilo, sino también en uno de Tebas, indica que este estatus de 'oferente' es común al menos a dos de las centros más importantes del mundo micénico. Este dato sugiere que debía de ser una ocupación frecuente en el ámbito de la religión micénica ${ }^{92}$.

\section{IMÁGENES}

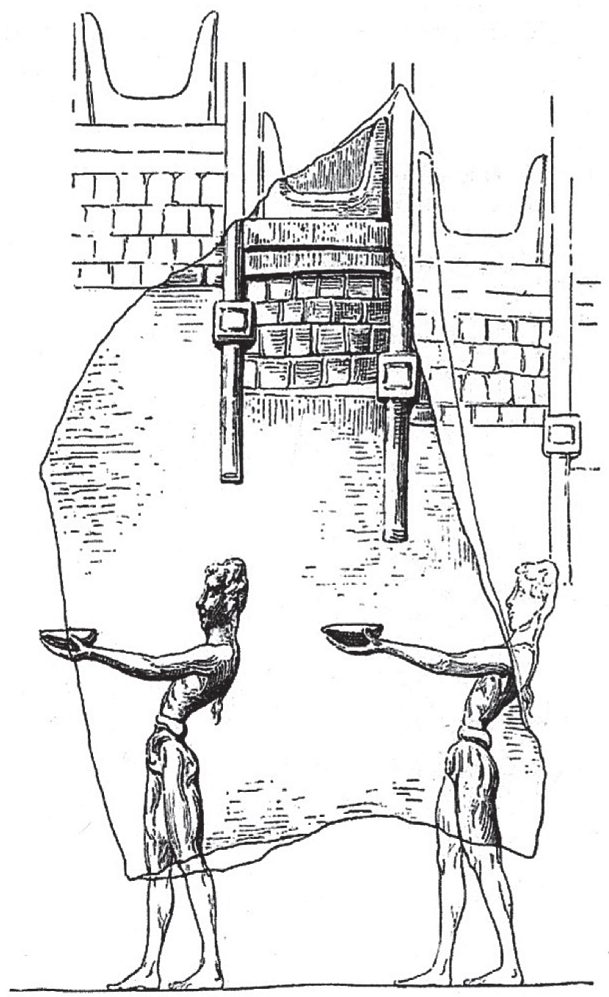

fig.1. Fragmento de relieve en un rhyton de esteatita de $\mathrm{Cnoso}^{93}$ con una especie de procesión con individuos que portan vasos del tipo $* 213^{V A S}$.

\footnotetext{
92 Para un paralelo entre micénicos e hititas en relación con el personal del templo que desempeña algún tipo de oficio ritual cf. Uchitel (2005).

93 Tomo la imagen de Evans (1928), p. 752, fig. 486.
} 


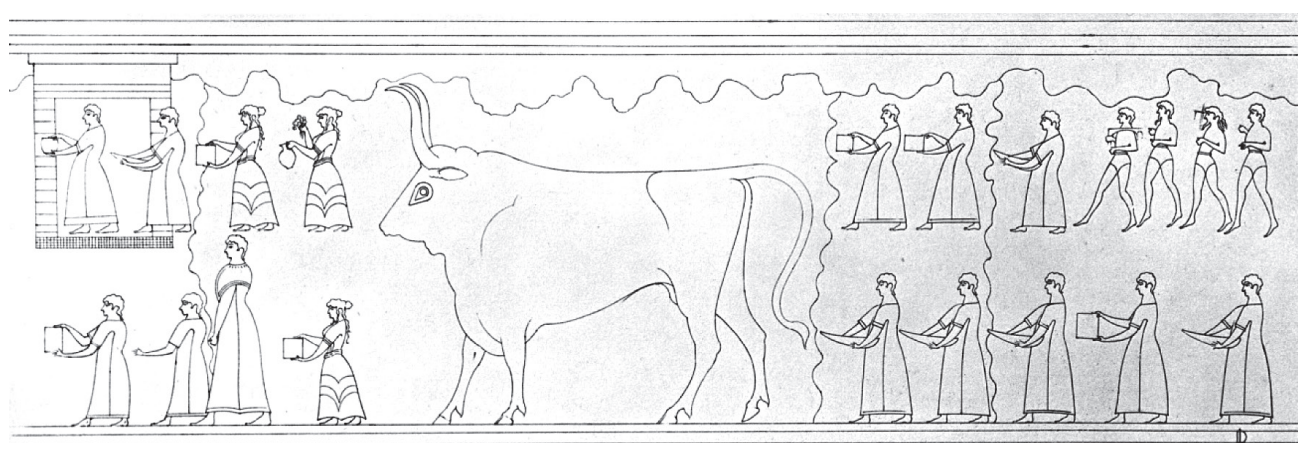

fig. 2. Reconstrucción del fresco del muro del vestíbulo del palacio de Pilo efectuada por Lang ${ }^{94}$.
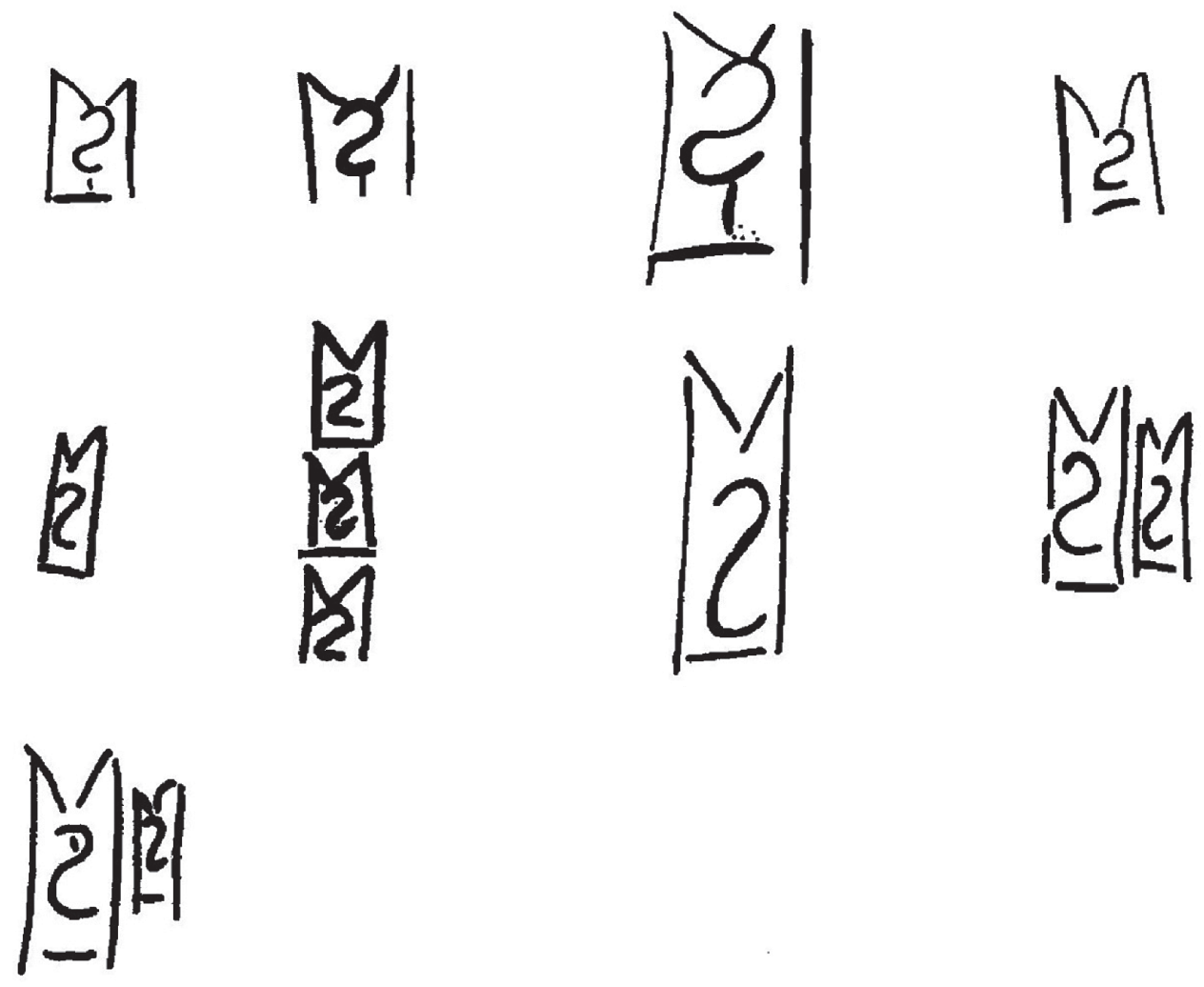

fig. 3. Ejemplos del ideograma $* 146^{95}$.

\footnotetext{
94 Lang (1969), P1. 119.

95 Tomo la imagen de Nosch (2012), p. 336.
} 


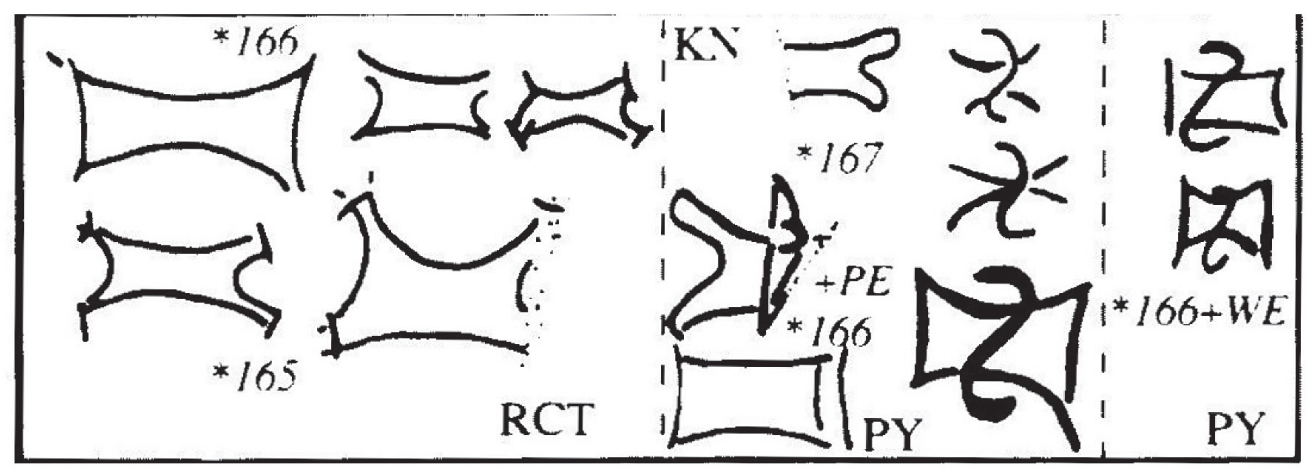

fig. 4. Ejemplos del ideograma *166, *165 y variantes ${ }^{96}$.

\section{APÉNDICE}

316

Tn 316

Recto

.1 po-ro-wi-to-jo ,

.2 pu-ro i-je-to-qe, pa-ki-ja-si, do-ra-qe , pe-re, po-re-na-qe

3 a-ke, po-ti-ni-ja AUR $* 215^{\text {VAS }} 1$ MUL 1

.4 ma-na-sa, AUR $* 213^{\text {VAS }} 1$ MUL 1 po-si-da-e-ja AUR $* 213^{\text {VAS }} 1$ MUL 1

.5 ti-ri-se-ro-e, AUR $* 216^{\mathrm{VAS}} 1$ do-po-ta AUR $* 215^{\mathrm{VAS}} 1$

$.6 \quad$ angustum

$.7 \quad$ vacat

\begin{tabular}{l|l}
.8 & vacat
\end{tabular}

.9
.10 $\quad$ pu-ro $\left\{\begin{array}{l}\text { vacat } \\ \text { vacat }\end{array}\right.$

$\omega$

$\Longrightarrow$

Verso

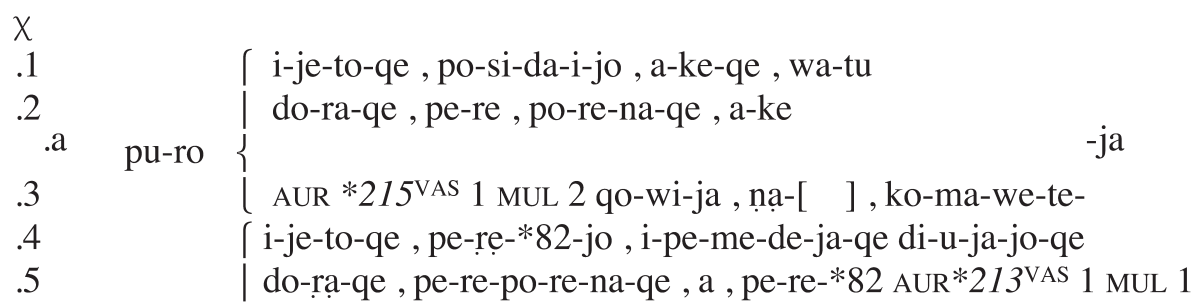

96 Tomo la imagen de Nosch (2012), p. 342. 


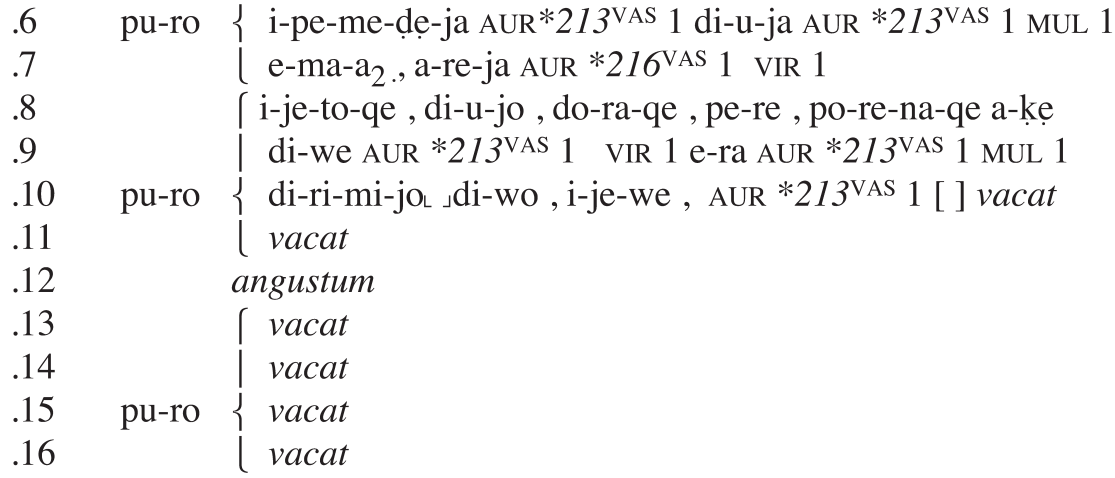

\section{BIBLIOGRAFÍA}

Balles, I. (2008), Nominale Wortbildung des Indogermanischen in Grundzügen: die Wortbildungsmuster ausgewählter indogermanischer Einzelsprachen. Band 1, Latein, Altgriechisch, Hamburg, Dr. Kovač.

Bennet, E. L (1979), «PU-RO vacant», en Colloquium Mycenaeum. Actes du Sixième Colloque International sur les textes mycéniens et égéens tenu à Chaumont sur Neuchâtel du 7 au 13 Septembre 1975, E. Risch - H. Mühlestein (eds.), Ginebra, Librairie Droz, 221-234.

Bernabé, A. (1987), Textos literarios hetitas, Madrid, Alianza Tres.

Bernabé, A. (2008), Dioses, héroes y orígenes del mundo, Madrid, Abada.

Bernabé, A. - Serrano, I. (2011), «Nuevos datos sobre la religión de la Tebas micénica: Las tablillas de la Odos Pelopidou», en EUSÉBEIA. Estudios de religión griega (Calderón, E.-Morales, A. eds.), Monografías y Estudios de la Antigüedad Griega y Romana 34, Signifer, 11-37.

Bernabé, A. - Luján, E.R. (en prensa), «Testi relativi alla lavorazione del cuoio».

Bonnechere, P. (1994), Le sacrifice humain en Grèce ancienne, Athenes-Liège, Centre International d'Étude de la Religion Grecque Antique.

Boyancé, P. (1966), «Dionysiaca, à propos d'une étude récente sur l'initiation dionysiaque», REA 65 (1-2), 33-61.

Buck, R. J. (1989), «Mycenean Human Sacrifice», Minos 24, 131-137.

Burkert, W. (2011), Griechische Religion der archaischen und klassischen Epoche, Stuttgart, Verlag H. Kohlhammer.

Chadwick, J. - Ventris, M. (1956, 1973²) Documents in Mycenaean Greek, Cambridge, University Press.

Chadwick, J. (1964), «Pylos Tablet Un 1322», en Mycenanean Studies. Proceedings of the Third International Colloquium for Mycenaean Stuides held at «Wingspread», 4-8 September 1961, E.L. Bennet (ed.), Madison, University of Wisconsin Press. 19-27.

Chadwick, J (1976), The Mycenaean World, Cambridge, University Press. 
Chantraine, P. (1933), La Formation des Noms en Grec Ancien, Paris, Librairie Ancienne Honoré Champion, Éditeur Édouard Champion.

Del Freo, M. (2005), «L'expression ka-ko na-wi-jo de la Tablette Jn 829 de Pylos», en EMPORIA. Aegeans in the Central and Eastern Mediterranean. Proceedings of the $10^{\text {th }}$ International Aegean Conference. 10e Rencontre égéenne internationale. Athens, Italian School of Archaeology 14-18 April 2004, R. Laffineur - E. Greco (eds.), Liège: Université de Liége; Austin: University of Texas, 793-803.

Duhoux, Y. (1975), «Les ideogrammes *168 et *181 du Linéaire B», Kadmos 14, 117-124.

Duhoux, Y. (1976), «Ideogrammes Textiles du Linéaire B», Minos 15, 116-132.

Duhoux, Y. (2008), «Mycenaean anthology», en A Companion to Linear B. Mycenaean Greek Texts and Their World vol. 1, Y. Duhoux-A. Morpurgo (eds.), Peeters, LouvainLa-Neuve, 243-395.

Evans, S. A. (1928), The Palace of Minos at Knossos II, vol. 2, London, Macmillan.

Franceschetti, A. (2012), «Gli ideogrami dei vasi in lineare B: analisi dell'ortografia, forme e dei materiali», en Études Mycéniennes 2010. Actes du XIIIE Colloque International sur les Textes Égéens, P. Carlier - Ch. De Lamberterie, et al. (eds.), Pisa-Roma, Fabrizio Serra Editore, 243-269.

Godart, L. - Sacconi, A. (1998), «Miceneo TU-WO, TU-WE-A», Atti della Academia Nazionale dei Lincei, $9^{\text {a }}$ serie, IX (4), 601-603

Godart, L. (2009), «I due scribi della tavoletta Tn 316», Pasiphae 3, 99-115.

Gulizio, J. (2000), «Hermes and $e-m a-a_{2}$. The continuity of his cult from the Bronze Age to the Historical Period», ŽAnt 50, 105-116.

Hiller, S. (1991), «Zu PY Tn 316», en Palaeograeca et Mycenea Antonino Bartoněk. Quinque et Sexagenario Oblata, Brno, Universitas Masarykiana Brunensis, 79-91.

Hughes, D. D. (1991), Human Sacrifice in Ancient Greece, London-New York, Routledge.

Jiménez San Cristóbal, A.I. (2008), «El ritual y los ritos órficos», en Orfeo y la tradición órfica. Un reencuentro, A. Bernabé - F. Casadesús (eds.), Madrid, Akal. 731-771.

Jouanna, J. (1992), «Libations et sacrifices dans la tragédie grecque», REG 105, 406-434.

Killen, J.T (1995), «Some Further Thoughts on «Collectors»», en Politeia. Society and State in Aegean Bronze Age (Aegaeum 12), Proceedings of the 5th International Aegean Conference / 5 e Rencontre égéenne internationale, University of Heidelberg, Archäologisches Institut, 10-13 April 1994, R. Laffineur - W. D. Niemeier (eds.), Leuven, Peeters, 213-226.

Killen, J.T. (2008), «The Commodities on the Pylos Ma Tablets», Colloquium Romanum. Atti del XII Colloquio Internazionale di Micenologia. Roma 20-25 Febbraio 2006, PisaRoma, Fabrizio Serra, 431-447.

Lang, M. (1969), The Palace of Nestor at Pylos in Western Messenia, vol. 2, Princeton, University Press.

Lejeune, M. (1997), Mémoires de philologuie mycénienne. 4e série 1969-1996, Roma, Isituti editoriale e poligrafici internazionali.

Marinatos, Sp. (1967), Kleidung: Haar-und Barttracht (Archaeologia Homerica), Göttingen, Vandenhoeck \& Ruprecht. 
Melena, J.L. (1975), Studies on some Mycenaean inscriptions from Knossos dealing with textiles, Salamanca, Universidad de Salamanca.

Melena, J.L. (2001), Textos griegos micénicos comentados, Vitoria-Gasteiz, Eusko Legebiltzarra.

Nagy, G. (1994-95), «A Mycenaean Reflex in Homer: ФOPHNAI», Minos 29-30, 171-175.

Nosch, M.L. - Perna, M. (2001), «Cloth in the cult», en POTNIA. Deities and Religion in the Aegean Bronze Age. Actes de la $5^{e}$ Recontre égénee international. University of Heilderberg, Archäologisches Institut, 10-13 April 1994, R. Laffineur, W.D. Niemeier (eds.), Austin 1995 (Aegaeum 12), 471-477.

Nosch, M.L. (2012), «The textile logograms in the Linear B tablets: Les idéogrammes archéologiques des textiles», en Études Mycéniennes 2010. Actes du XIIIE Colloque International sur les Textes Égéens, P. Carlier - Ch. De Lamberterie, et al. (eds.), Pisa Roma, Fabrizio Serra Editore, 303-345.

Palaima, Th. G. (1995), «The Last days of the Pylos Polity», en Politeia. Society and State in Aegean Bronze Age (Aegaeum 12), Proceedings of the 5th International Aegean Conference / 5 e Rencontre égéenne internationale, University of Heidelberg, Archäologisches Institut, 10-13 April 1994, R. Laffineur and W. D. Niemeier (eds.), Leuven, Peeters, 623-634.

Palaima, Th. G. (1996-97), «po-re-na: A Mycenaean Reflex in Homer? A I-E Figure in Mycenaean?» Minos 31-32, 303-312.

Palaima, Th. G. (1999), «Kn 02- Tn 316», en Floreant Studia Myceanea. Actes des X Internationalen Mykenologischen Colloquiums in Salzburg vom 1-5 Mai 1995, S. DegerJalkotzy, S. Hiller, O. Panagl. (eds.), Wien, Verlag der Österreichischen Akademie der Wissenschaften, 437-463.

Palmer, L.R. (1963), The Interpretation of Mycenaean Greek Texts, Oxford, University Press.

Sacconi, A. (1967), «Gli ideogrammi per la pelle e per il cuoio nei testi micenei», SMEA 3, 99-134.

Sacconi,A. (1987), «La Tavoletta di Pilo Tn 316. Una Registrazione de Carattere Eccezionale?», en Studies in Mycenaean and Classical Greek Presented to John Chadwick (Minos 2022), J. Killen - J. L. Melena - J.P. Olivier (eds.), Salamanca, Universidad de Salamanca, 551-556.

TOP I: Aravantinos, V.L. - Godart. L. - Sacconi, A. (2001), Thèbes. Fouilles de la Cadmée I. Les tablettes en linéaire B de la Odos Pelopidou, éditon et commentaire, Pisa, Istituti editoriali e poligrafici internazionali.

Rehak, P. (1996), «Breechcloths, Kilts, and the Keftiu Paintings», AJA 100 (1), 35-51.

Ruijgh, C. (2004), «Á propos des nouvelles tablettes de Thèbes, I. Les trois divinités $m a-k a$, o-po-re-i et ko-wa et les trois subordonnées temporelles dans la série Fq», Mnemósyne 57 (1), 1-44.

Ruipérez, M. S. - Melena, J. L. (1990), Los griegos micénicos, Madrid, Historia 16.

Ruiz Abad, C. (2013), Papeles semánticos y procedimientos de formación de palabras: los nombres de Instrumento y Ubicación en griego antiguo en perspectiva tipológica, tesis doctoral inédita leída en la Universidad Complutense de Madrid. 
Sakellarakis, Y. - Sapouna Sakellaraki, E. (1981), «Drama of Death in a Minoan Temple», National Geographic 159 (2), 205-222.

Sokolowski, F. (1969), Lois sacrées des cités grecques, Paris, E. de Boccard.

Uchitel, A. (2005), «Assignment of personnel to cultic households in Mycenaean Greece and the Hitite Empire (PY TN 316 and KBO XVI.65)», Kadmos 44, 51-59.

Vandenabeele, F. - Olivier. J.P. (1979), Les idéogrammes archéologiques du linéaire B, París, Geuthner.

Weilhartner, J. (2005), Mykenische Opfergaben: nach Aussage der Linear B-texte, Wien, Österreichischen Akademie der Wissenschaften.

Willi, A. (1994-95), «do-ra-qe pe-re po-re-na-qe a-ke: An Indo-European Figure in Mycenaean?», Minos 29-30, 177-185. 